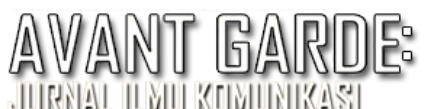

\title{
Motif Penggunaan Fitur Stories Highlight Instagram sebagai Memori Media bagi Generasi Milenial
}

\author{
Nabila Putri Aldira \\ nabila.putri91@ui.ac.id \\ Universitas Indonesia, Jl. Salemba Raya 4, Jakarta, Indonesia
}

Submitted: 10 October 2020, Revised: 16 November 2020, Accepted : 04 December 2020

\begin{abstract}
Abstrak
Evolusi teknologi informasi dan komunikasi membawa perubahan pada cara pandang masyarakat dalam memaknai sesuatu. Masyarakat modern sudah beralih pada penggunaan digital yang praktis dan dinamis. Bentuk komunikasi dan penyimpanan memori atau kenangan masa lalu pun turut berubah menjadi terdigitalisasi. Penelitian ini bertujuan untuk mengeksplorasi motif penggunaan fitur stories highlight Instagram sebagai bentuk memori media bagi generasi milenial. Penelitian ini menggunakan teori fenomenologi Alfred Schütz, konsep media baru, Instagram dan konsep memori media. Dengan menggunakan paradigma interpretif, pendekatan kualitatif, metode penelitian fenomenologi dan desain penelitian deskriptif, penelitian ini menemukan hasil bahwa terdapat motif sebab (because-motives) dan motif agar (in-order-to motives). Hasil motif sebab (becausemotives) penggunaan stories highlight Instagram bagi generasi milenial, disebabkan oleh mengikuti teman dan tren, karena memanfaatkan teknologi media baru, dan karena fitur stories highlight Instagram memiliki lebih banyak opsi yang menarik untuk menyampaikan pesan dan menyimpan memori daripada fitur lain. Terdapat pula hasil mengenai motif agar (in-order-to motives) pada penggunaan stories highlight Instagram bagi generasi milenial yaitu agar membentuk album digital yang terkonsep dan tersusun, agar dapat show off kepada orang lain, dan agar dapat bersyukur atas kejadian yang pernah terjadi di masa lalu. Serta terdapat pula hasil mengenai makna yang ditemukan dari penggunaan fitur stories highlight Instagram bagi generasi milenial yaitu sebagai album digital untuk menyimpan memori yang pernah terjadi di masa lalu. Kesimpulannya bahwa stories highlight Instagram bagi generasi milenial merupakan cara berkomunikasi melalui album digital sebagai pengantar pesan pada orang lain di era modern.
\end{abstract}

Kata kunci: motif, memori media, milenial, stories highlight instagram.

\section{Motives For Using Instagram Highlight Stories Feature As Media Memory For Millennial Generation}

\begin{abstract}
The evolution of information and communication technology has brought changes to the way people perceive things. Modern society has switched to practical and dynamic digital use. The form of communication and memory storage or past memories also changes to become digitalized. This study aims to explore about motives for using Instagram stories highlight feature as a form of media memory for millennial generation. This study uses the phenomenological theory of Alfred Schütz, the concept of new media, Instagram and media memory. By using the interpretive paradigm, qualitative approach, phenomenological research methods and descriptive research design, this study found that there are because-motives and in-order-to motives. The result of because-motives in using Instagram highlight stories for millennial generation, are caused by following friends and trends, it takes advantage of new media technology, and Instagram highlight stories has more interesting options to convey messages and save memories than other features. There are also results about in-order-to motives in using Instagram highlight stories for millennial generation, to form a conceptual and structured digital album, in order to show off to others, and to be grateful for experiences that have happened in the future. And there are also found a result about the meaning of using Instagram stories highlight for millennial generation, as a digital album to save memories that have happened in the past. The conclusion about Instagram highlight stories for millennial generation is a way of communicating through digital albums as an introduction to messages to other people in the modern era.
\end{abstract}


Key words: instagram highlight stories, media memory, motives, millennial

\section{PENDAHULUAN}

Manusia merupakan aktor sosial yang terus bertumbuh. Dalam kehidupannya manusia mengalami pengalaman yang menghasilkan makna bagi yang memerankannya. Alfred Schütz seorang filsuf yang mengembangkan pemikiran dari Husserl mengenai fenomenologi, menyatakan bahwa fenomenologi sosial merupakan suatu fenomenologi yang berusaha memahami makna pembentukan tindakan manusia yang khas (Vieira et al., 2013). Pada setiap tindakan yang dikembangkan, ada perasaan yang dengan sengaja berusaha untuk memenuhi harapan dan kebutuhan (Vieira et al., 2013). Dalam melakukan tindakan, individu atau aktor sosial membangun makna. Sebagian besar didorong oleh motivasi untuk mendapatkan informasi tentang peluang atau risiko di mana situasi memerlukan hasil tindakannya (Trujillo, 2018). Motif mengacu pada alasan perilaku yang mendasari tindakan (Guay et al., 2010). Tindakan manusia dapat dipahami dengan merujuk pada motif khas mereka, yang memunculkan makna subjektif atau tidak mendasar dari tindakan yang dilakukan aktor. (Walgito, 2010) menyatakan bahwa motif merupakan dorongan dalam diri yang timbul dikarenakan adanya kebutuhan-kebutuhan yang ingin dipenuhi. Semua tingkah laku manusia yang melingkupi penggerak, alasan-alasan atau dorongan dalam diri manusia yang menyebabkan manusia berbuat sesuatu. Karena itu motif diartikan sebagai kekuatan yang terdapat dalam diri manusia yang mendorong dirinya untuk berbuat sesuatu (Walgito, 2010).

Fenomenologi Schütz menyatakan bahwa terdapat dua hal yang menjadi motif aktor sosial dalam melakukan tindakan (Muzzetto, 2006). Schütz mengklasifikasikan motif menjadi dua bagian, yakni because-motives (Weil-Motives) dan in-order-to motives (Um-zuMotives). Because-motives adalah kondisi latar belakang dan pengalaman yang menyebabkan aksi atau tindakan (Gunderson et al., 2020). Because-motives adalah latar belakang, alasan masa lalu yang mempengaruhi orang untuk melakukan tindakan tertentu (Muzzetto, 2006). Sementara in-order-to motives adalah motif agar atau tujuan yang berdasarkan pada motif masa lalu untuk kejadian di masa depan (Muzzetto, 2006). Because-motives dan in-order-to motives membentuk ikatan dalam rantai relevansi motivasi. Because-motives membangun kegiatan atau tindakan terpenting individu. Dan in-order-to motives berasal dari kegiatan atau tindakan terpenting yang sudah ada (Gunderson et al., 2020). Selain itu terdapat pula makna yang juga termasuk dalam pemikiran Schütz. Makna adalah pengalaman yang dialami aktor sosial (Muzzetto, 2006). Makna berkaitan dengan aspek apa yang dialami oleh individu atau aktor sosial, yang terdapat pada tindakan (Muzzetto, 2006). Bagi Schütz, makna juga membutuhkan kesadaran akan pengalaman itu. Schütz menyatakan bahwa makna dari setiap tindakan adalah sesuatu terkait yang diproyeksikan (Muzzetto, 2006). Pengalaman hidup tidak hanya bagaimana pengalaman itu dialami, tetapi juga bagaimana peran makna pada pengalaman tersebut (Qutoshi, 2018). Alfred Schütz membuat definisi tentang pengalaman dalam perspektif sosial. Dalam pandangan Schütz, makna dari pengalaman individu didapatkan dari tindakan sosial yang dilakukan (Rakhmawati, 2019).

Perkembangan teknologi informasi dan komunikasi membawa perubahan yang signifikan pada cara masyarakat memandang dan memaknai sesuatu. Formulasi McLuhan 
pada 1950-an menjadi ramalan bagi utopia internet di 1990-an, yang menyatakan bahwa zaman McLuhan akhirnya tiba dengan dimulainya informasi instan yang disediakan oleh internet (Olubunmi, 2016). Perkembangan ini dikenal dengan hadirnya media baru, yang muncul pada abad ke-19 dengan karakteristik peralihan dari bentuk media analog ke media digital dengan penggunaan internet (Littlejohn \& Foss, 2009). Di mana satu perangkat terhubung ke seluruh dunia dengan mengklik mouse atau ketukan pada perangkat seluler yang disebut dengan istilah global village (Olubunmi, 2016). Karenanya, muncul masyarakat informasi modern sebagai hasil dari pengembangan inovasi, teknologi baru dan implikasi sosial (Hauer, 2017). Perubahan ini terjadi berdasarkan pengalaman individu atau aktor sosial yang memerankannya. Teknologi komunikasi ini didasarkan pada pengkodean dan pemrosesan data digital/numerik (Hauer, 2017). Untuk merekam informasi (karakter, gambar, suara, deskripsi tindakan), teknologi digital menggunakan pengkodean numerik. Digitalisasi adalah proses mengubah informasi menjadi kode dengan sistem biner (Hauer, 2017).

Ditegaskan lebih lanjut, bahwa kajian media baru mengalihkan banyak perhatiannya pada ontologi media digital (Littlejohn \& Foss, 2009). Kemampuan pertukaran informasi yang bermakna oleh media baru memberikan partisipasi lebih aktif pada media. Pendapat Jenkins bahwa konsumen convergence media cenderung terhubung secara sosial dikarenakan dapat mengunggah kontennya sendiri serta memilih dari beragam informasi yang terfragmentasi (Littlejohn \& Foss, 2009).

Karakteristik media baru yaitu menggunakan akses internet, termediasi, interaktif, mudah dicari dan diproses, serta dapat diakses secara individual (Logan, 2013). Media baru memungkinkan pengguna untuk membuat, memodifikasi dan berbagi konten, menggunakan alat yang relatif sederhana yang seringkali gratis atau murah (Olubunmi, 2016). Media baru membutuhkan komputer atau perangkat seluler yang dapat mengakses internet. Dengan World Wide Web yang didukung oleh internet, relevansi media lama mulai berkurang (Olubunmi, 2016). Perkembangan ini menunjukkan digitalitas sebagai langkah evolusi lain dalam teknologi, yang memungkinkan platform online berbasis perangkat lunak, seperti YouTube, SoundCloud, Twitter dan Instagram disebut sebagai media digital (McMullan, 2017).

Salah satu media baru yang populer saat ini adalah Instagram. Instagram merupakan aplikasi media sosial populer di kalangan anak muda di dunia dengan rentang usia 18 - 29 tahun (Huang \& Su, 2018). Instagram dirilis pada tahun 2010 oleh Kevin Systrom dan Mike Kreiger di San Fransisco (Amaral, 2015), yang merupakan platform jejaring sosial yang menggunakan foto dan video sebagai alat komunikasi. Komunikasi yang divisualisasikan telah menjadi cara komunikasi yang disukai oleh kaum muda modern (Huang \& Su, 2018). Instagram berada pada urutan ke aplikasi seluler berdasarkan kategori pengguna aktif (Kemp, 2020).

Instagram memberi pengguna kemampuan untuk merekam video hingga 60 detik (ini meningkat dari 15 detik pada 2016) melalui ponsel (Macon, 2017). Aplikasi ini memiliki beragam fitur untuk memberikan informasi kepada pengguna. Beberapa fitur umum yang digunakan pada Instagram (Macon, 2017), yaitu (a) photo profile: foto dipilih oleh pengguna sebagai foto identitas dan dapat diubah sesering yang diinginkan pengguna, (b) username: nama untuk pengguna, yang mengidentifikasi penulis posting, (c) like: jumlah pengguna yang 
menyukai foto, (d) comment: komentar yang ditulis oleh pengguna lain pada postingan sebagai tanggapan terhadap posting asli, (e) caption: keterangan berbentuk teks atau emoji yang ditambahkan oleh penulis pos yang ditampilkan di bawah postingan, (f) mention: membuat link dari pos ke akun pengguna yang dituju, $(\mathrm{g})$ timeline/feed: format foto atau video yang diunggah pengguna pada laman utama profil yang dapat disertai dengan caption, (h) story: fitur yang hadir pada tahun 2016 dengan hanya berdurasi 24 jam kemudian lenyap dari pengguna lain, dengan format foto atau video yang berdurasi 5 - 15 detik, dan opsi filter yang beragam. Instagram story telah menjadi fenomena dalam masyarakat. Terdapat 500 juta pengguna harian Instagram story yang meningkatkan dari 400 juta dari tahun sebelumnya (Bohang, 2019).

Instagram berupaya menghadirkan dan mengembangkan fitur-fitur unggulannya, salah satunya Instagram story. Pada tahun 2017, Instagram merilis dua fitur baru secara bersamaan yakni fitur stories archive dan fitur stories highlight (Josina, 2017). Fitur stories highlight memungkinkan pengguna untuk merangkum hasil Instagram stories ke dalam kategori pilihan. Maksimum stories pada satu highlight yakni 100 stories. Fitur ini terletak di bagian bawah biografi pengguna pada laman profil Instagram (Kertamukti et al., 2019). Stories highlight dapat bertahan lebih lama dibandingkan Instagram stories di laman profil pengguna hingga lebih dari 24 jam selama pengguna menginginkan gambar/video yang diunggahnya untuk ditampilkan (Josina, 2017). Pada penggunaan stories highlight Instagram, terdapat pilihan untuk membuat sampul (cover) sendiri atau mengikuti format asli dari Instagram.

Pada fitur Instagram stories yang mendahului stories highlight, memungkinkan pengguna untuk mengunggah foto dan/atau video yang secara otomatis akan tetap tersedia selama 24 jam dan dapat divisualisasikan oleh siapa saja yang mengikuti akun pengguna (Amâncio, 2017). Pengguna yang tidak lagi ingin mengunggah foto dan video yang dapat diakses selamanya, dapat memilih opsi untuk membiarkan unggahannya hanya selama 24 jam untuk dilihat pengguna lain atau ingin dibuat lebih lama dari 24 jam dengan dimasukkan dalam kumpulan pada fitur stories highlight. Story adalah tren baru di media sosial yang dipelajari untuk berbagai tujuan, seperti memahami transformasi media sosial dan hubungan antara dunia online dan offline (Amâncio, 2017). Stories highlight ini juga menjadi fenomena dalam masyarakat karena mayoritas pengguna Instagram menggunakan fitur ini dalam akun mereka. Dalam hasil penelitian (Togar et al., 2019) terdapat lima dari enam orang pengguna Instagram menggunakan highlight pada laman akun mereka.

Perkembangan teknologi dan digitalisasi kini sudah mendominasi penggunaan, baik cara berkomunikasi maupun penyimpanan informasi termasuk memori. Memori dapat didefinisikan sebagai penyimpanan dan penarikan kembali informasi (Seyfi \& Uzuncarsili Soydas, 2017). Memori merupakan bentuk kenangan masa lalu yang tersimpan dalam pikiran manusia. Namun tidak semua memori dapat disimpan dengan baik oleh otak, sehingga membutuhkan tempat penyimpanan lain (Seyfi \& Uzuncarsili Soydas, 2017).

Sementara, memori media adalah eksplorasi sistematis masa lalu kolektif yang diriwayatkan oleh media, melalui penggunaan media dan tentang media (Neiger et al., 2011). Ketersediaan basis data daring yang belum pernah terjadi sebelumnya yang menawarkan dokumentasi berbasis media di masa lalu, kemudahan versi masa lalu yang terdistorsi 
sekarang dapat dibuat dan disebarluaskan (Neiger et al., 2011). Memori bukanlah objek statis yang hanya diingat atau dimiliki, tetapi proses aktif menempatkan diri individu dalam kaitannya dengan masa lalunya (Kuhn, 2010). Memori dapat memungkinkan individu untuk mengingat kembali pengalamannya, serta memeriksa dan menggunakannya untuk berbagai tujuan (Özkul \& Humphreys, 2015). Pekerjaan memori melibatkan produksi objek, dalam hal ini foto dan video, dengan tujuan untuk mendokumentasikan dan mengomunikasikan apa yang terjadi (Özkul \& Humphreys, 2015). Pengguna lebih mementingkan apa yang mereka unggah dan bagaimana mereka mengekspresikan pesan mereka dalam unggahan (Serafinelli, 2017)

Konsep memori yang didefinisikan dengan berbagai cara dalam berbagai disiplin ilmu pada dasarnya dapat didefinisikan sebagai penyimpanan dan penarikan kembali informasi. Memori semacam ini melibatkan individu berbagi dengan individu lain yang hidup dalam periode waktu yang sama. Itu terjadi dan menghilang dalam waktu, dan masuk ke memori orang lain ketika pemiliknya meninggal. Definisi tersebut untuk memori komunikasi menjelaskan entitas memori di media sosial saat ini (Seyfi \& Uzuncarsili Soydas, 2017). (Macon, 2017) mengungkapkan internet menjadi menarik karena menyajikan teks, foto dan video dengan resolusi yang cukup bagi pengguna untuk diproses secara efisien.

Dalam realitasnya, pengguna aktif Instagram saat ini didominasi oleh generasi milenial. Dengan persentase pengguna sebanyak 69,3\% pada Mei 2020 (Mustafa, 2020). Generasi milenial merupakan generasi yang lahir pada rentang tahun 1980 hingga 2000 (Budiati et al., 2018). Yang memiliki karakteristik dekat dengan media sosial, kreatif, efisien, punya passion, produktif, dinamis, ingin serba cepat, open minded, kritis dan berani (Budiati et al., 2018). Generasi milenial memiliki peluang dan kesempatan berinovasi yang sangat luas. Istilah milenial pertama kali dicetuskan oleh William Strauss dan Neil pada tahun 2000 (Budiati et al., 2018). Generasi milenial juga disebut sebagai generasi Y (Budiati et al., 2018). Berdasarkan definisi, persentase dan karakteristik tersebut, menjadi alasan penulis untuk menjadikan generasi milenial sebagai subjek pada penelitian ini. Karena generasi milenial merupakan pengguna aktif yang mendominasi Instagram saat ini, dan hal tersebut dapat menjadi representasi dari penelitian ini.

Penelitian ini beranjak dari fenomena saat ini pada pengguna media sosial khususnya Instagram, dan untuk mengembangkan penelitian sejenis terdahulu dari tesis program master oleh Amâncio yang berjudul Put it in your Story: Digital Storytelling in Instagram and Snapchat Stories pada tahun 2017. Penelitian ini menggunakan teori naratif dengan menginformasikan konsep digital storytelling pada penerapannya di media Instagram dan Snapchat. Dengan metode kualitatif, penelitian ini bertujuan untuk memahami yang diposting pengguna dalam stories mereka dan bagaimana mereka memanfaatkan fitur tersebut untuk menceritakan kisah atau cerita mereka. Hasil penelitian mengindikasikan bahwa terdapat pola bertema mengikuti struktur naratif pada fitur story di Instagram dan Snapchat. Hasil selanjutnya menunjukkan bahwa storyteller pada Instagram dan Snapchat menggunakan tujuh cara untuk menampilkan kisah atau cerita mereka dalam membuat narasi digital storytelling, yaitu dengan menggunakan gambar, teks, video, emoji, coretan (doodles), informasi instan dan filter. 
Penelitian kedua dari Kertamukti, Nugroho dan Wahyono dengan judul Kontruksi Identitas melalui Stories Highlight Instagram Kalangan Kelas Menengah pada tahun 2019. Penelitian ini menggunakan teori konstruksi identitas Berger dan konsep Instagram sebagai media digital. Penelitian ini juga menggunakan metode kualitatif, dengan tujuan untuk mengetahui konstruksi identitas lima informan dari kalangan kelas menengah melalui stories highlight Instagram. Hasil penelitian menunjukkan bahwa informan kelas menengah menggunakan Instagram sebagai media visual yang menghadirkan simbol-simbol untuk menunjukkan suatu identitas, yang disampaikan informan mengenai refleksi waktu luang kegiatan yang mereka lakukan seperti hobi dan kegiatan lain untuk mengisi waktu luang.

Pembaharuan dari penelitian ini yaitu penerapan konsep memori media pada media baru. Sedangkan mayoritas pada penelitian terdahulu konsep memori media dilakukan pada media massa seperti dokumenter televisi, film, maupun surat kabar. Penelitian ini melihat konsep memori media pada media baru, dikaitkan dengan teori fenomenologi Alfred Schütz. Sementara pada penelitian sebelumnya, kajian sejenis menggunakan teori agenda setting dan storytelling.

Dengan hadirnya stories highlight sebagai fitur yang marak digunakan oleh pengguna Instagram, menimbulkan tanda tanya mengenai motif penggunaan fitur ini sebagai bentuk memori media. Sehingga penelitian ini bertujuan untuk mengetahui serta mendeskripsikan motif penggunaan stories highlight Instagram sebagai memori media bagi milenial, yang dilihat dari sisi komunikasi dan pandangan pengguna. Penelitian ini berfokus pada bagaimana motif subjek dalam melakukan tindakan terkait dengan penggunaan stories highlight Instagram. Apa alasan subjek melakukan tindakan dan mengapa subjek melakukan tindakan atas motif tersebut. Penelitian ini juga berfokus pada pengguna Instagram generasi milenial.

Penelitian ini diharapkan dapat memberikan sumbangsih cakrawala baru bagi masyarakat, serta mampu menjembatani penelitian sebelumnya dan menjadi kebaharuan pada bidang kajian ilmu komunikasi, terutama memori media pada media baru.

\section{METODE PENELITIAN}

Paradigma merupakan hal mendasar dari sebuah penelitian. Paradigma penelitian adalah sistem kepercayaan dasar atau pandangan dunia yang membimbing seorang peneliti (Halik, 2018). Fungsi paradigma dalam penelitian tidak hanya dalam hal memilih metode, namun juga dalam menentukan cara-cara fundamental secara ontologis dan epistemologis (Halik, 2018). Dalam penelitian ini, paradigma yang digunakan adalah paradigma interpretif. Istilah lain paradigma interpretif adalah konstruktivis (Creswell, 2013). Dalam paradigma ini, individu membangun pemahaman atas dunia yang ditempatinya, yang didasarkan pada pengalaman dan pengetahuan sebelumnya. Dan peneliti akan dibawa untuk memahami pembentukan atau konstruksi dari realitas tersebut. Interpretivis percaya pada berbagai realitas yang dibangun secara sosial. Epistemologi interpretatif bersifat subjektif (Rehman \& Alharthi, 2016). Penelitian ini menganut paradigma interpretif sebab melihat konstruksi dari pengalaman individu atau aktor sosial yang menjalani realita kehidupan sosialnya.

Dari segi pendekatan, penelitian ini menggunakan pendekatan kualitatif. Dunia dalam objek penelitian kualitatif tidak hanya berfokus pada personalnya saja, melainkan juga pada bentuk-bentuk karya fisik seperti dokumen, hasil wawancara, foto, rekaman, bahkan catatan 
memo. Pendekatan penelitian kualitatif memiliki karakteristik tersendiri, yakni fenomena atau peristiwa yang diteliti lebih bersifat umum, fleksibel, dinamis, eksploratif, dan terus berkembang selama penelitian berlangsung (Creswell, 2013).

Penelitian ini menggunakan metode penelitian fenomenologi. Penelitian dengan teknik fenomenologi mempelajari tentang struktur kesadaran yang dibangun berdasarkan pengalaman orang pertama, dengan kata lain fenomenologi merefleksikan dunia kehidupan orang lain untuk memahami makna dunia yang diberikan kepada sudut pandang orang pertama (Finlay, 2012).

Asumsi dasar dari fenomenologi ada tiga yaitu pengetahuan adalah kesadaran, makna tergantung dari fungsi makna terhadap pengalaman individu, dan bahasa sebagai sarana makna. Setiap pengetahuan yang didapatkan manusia merupakan hasil dari pengalaman sadar melalui penginderaan melalui penglihatan, pendengaran, sensasi sensoris lainnya (Rakhmawati, 2019). Disari dari (Yusuf, 2014), dalam metode fenomenologi terdapat langkah-langkah dalam melakukan penelitian yaitu menemukan fenomena penelitian yang akan diteliti melalui penelitian kualitatif, menganalisis fenomena tersebut, menentukan subjek yang akan diteliti, pengumpulan data dan pembuatan catatan, menganalisis data hingga penulisan laporan.

Desain yang digunakan dalam penelitian ini adalah desain penelitian deskriptif. Penelitian deskriptif bertujuan untuk menggambarkan suatu karakteristik atau fungsi dari sesuatu (Neuman, 2014). Secara deskriptif penelitian ini bertujuan untuk mendeskripsikan motif dan makna penggunaan fitur stories highlight Instagram dengan berlandaskan teori fenomenologi Alfred Schütz dan konsep media baru serta memori media dari perspektif komunikasi. Peneliti mendeskripsikan pengalaman informan ke dalam teori dan konsep yang dipilih.

Yang menjadi objek penelitian adalah motif penggunaan fitur stories highlight Instagram sebagai memori media. Sementara subjek penelitian adalah generasi milenial sebagai pengguna Instagram yang telah memenuhi kriteria menjadi informan, sebanyak dua orang. Informan yang diwawancarai terdiri dari dua orang, yang mana sesuai dengan lima karakteristik yang sudah ditetapkan sebelumnya yaitu milenial yang berusia usia 18 - 29 tahun (Huang \& Su, 2018), selain itu dipilih berdasarkan kriteria berikut yaitu mempunyai akun Instagram di atas lima tahun penggunaan, mempunyai pengikut (followers) lebih dari 1.000 akun, aktif di Instagram minimal lima kali dalam seminggu, menggunakan fitur stories highlight Instagram lebih dari tiga kategori highlight.

Dua informan tersebut adalah Adya Rosyada Yonas, perempuan berusia 23 tahun dengan status mahasiswa (informan 1). Dan Agrian Ratu Randa, laki-laki berusia 23 dengan status pekerja swasta. Berikut tampilan profil Instagram kedua informan, yang menampilkan stories highlight pada akun masing-masing. 
Sumber: Instagram, 2020

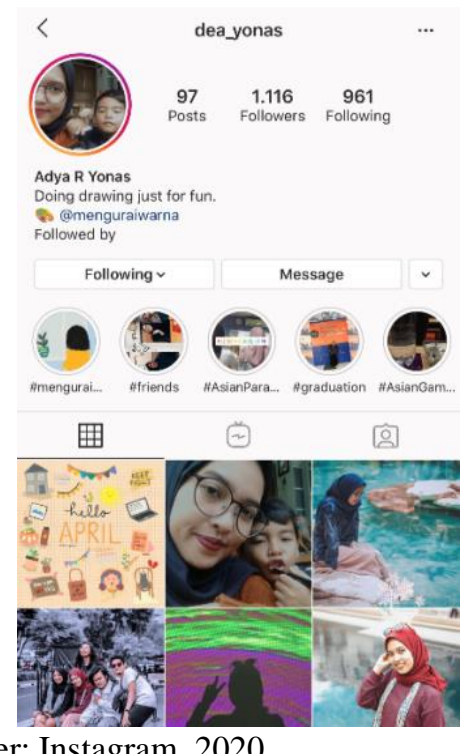

Gambar 1 Foto Halaman Profil @dea_yonas

(informan 1)

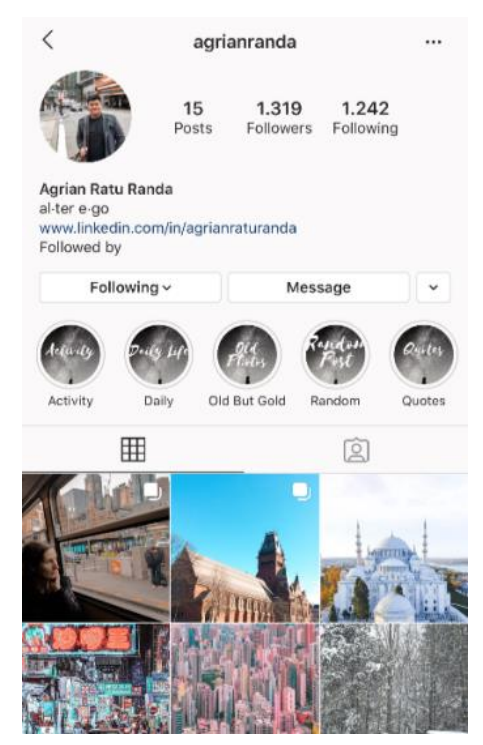

Gambar 2 Foto Halaman Profil @agrianranda

(informan 2)

Dikarenakan saat penelitian ini berlangsung, sedang diberlakukannya Pembatasan Sosial Berskala Besar (PSBB) akibat Pandemi Covid-19, maka wawancara dilakukan secara daring kepada dua orang informan secara terpisah dan pada hari yang berbeda. Wawancara pertama dengan informan dilakukan pada akhir Mei 2020 melalui aplikasi Zoom, kemudian dilakukan wawancara lanjutan untuk memperkuat data penelitian. Penggunaan aplikasi daring (Zoom) merupakan salah satu keterbatasan penelitian, yang disebabkan oleh situasi pandemi Covid-19 saat ini. Agar penelitian tetap berjalan sesuai prosedur dan tetap kredibel, peneliti melakukan wawancara melalui aplikasi Zoom. Pengumpulan data juga dilakukan melalui observasi, yaitu dengan mengikuti tren stories highlight Instagram berupa foto dan/atau video pada akun informan dan arsip lain selama beberapa bulan, yang kemudian dianalisis.

Uji keabsahan data dilakukan dengan teknik triangulasi data, dimana pemeriksaan keabsahan data melihat dan memanfaatkan sesuatu dari berbagai sudut pandang untuk keperluan akurasi (Neuman, 2014). Teknik triangulasi yang digunakan dengan pemeriksaan data melalui sumber sekunder berupa kajian literatur dan dokumentasi.

\section{HASIL DAN PEMBAHASAN}

Penelitian ini menemukan motif penggunaan fitur stories highlight Instagram sebagai memori media bagi generasi milenial. Motif merupakan kekuatan yang terdapat dalam diri manusia yang mendorong dirinya untuk berbuat sesuatu (Walgito, 2010). Motif mengacu pada alasan perilaku yang mendasari tindakan manusia (Guay et al., 2010). Fenomenologi berdasarkan pemikiran Alfred Schütz didasarkan pada pengalaman dalam kehidupan seharihari para aktor sosial yang menjalaninya (Trujillo, 2018). Dalam penelitian ini ditemukan hasil pemikiran dari teori fenomenologi Alfred Schütz yang membagi motif menjadi motif sebab (because-motives) dan motif agar (in-order-to motives) dari dua informan yang sesuai dengan kriteria yang sudah ditetapkan. 
Selain itu ditemukan pula makna fitur stories highlight Instagram sebagai memori media bagi generasi milenial, yang mana makna juga merupakan turunan dari motif menurut Alfred Schütz. Pengalaman hidup tidak hanya bagaimana pengalaman itu dialami, tetapi juga bagaimana peran makna pada pengalaman tersebut (Qutoshi, 2018).

\section{Because-Motives}

Because-motives adalah kondisi latar belakang atau alasan masa lalu yang menyebabkan aksi atau tindakan oleh aktor sosial (Gunderson et al., 2020). Dari hasil wawancara dengan dua informan, didapatkan beberapa alasan masa lalu mengapa informan menggunakan fitur stories highlight Instagram. Pertama, karena mengikuti teman. Informan 1 dan informan 2 mengakui bahwa faktor dorongan dikarenakan melihat teman mereka menggunakan fitur stories highlight, yang menjadi pemicu bagi kedua informan untuk menggunakan fitur ini. Hal ini sejalan dengan hasil penelitian sebelumnya mengenai fenomena story Instagram, yang mana lima dari enam informan menggunakan stories highlight pada halaman akun Instagram mereka (Togar et al., 2019). Peneliti juga melakukan observasi dengan melihat akun Instagram yang diikuti informan, dengan hasil bahwa mayoritas menggunakan stories highlight di halaman akun mereka. Sebagaimana jawaban pertama informan, bahwa ini tidak terlepas dari fenomena mengikuti tren yang sedang terjadi di awal munculnya fitur stories highlight Instagram. Kedua, informan mengaku menggunakan fitur ini karena memanfaatkan teknologi yang ada. Pemanfaatan ini dinilai menjadi suatu hal baru dari adanya perkembangan teknologi dalam menyimpan kenangan bagi informan terutama di platform digital. Kemajuan teknologi informasi dan komunikasi membawa pengaruh pada masyarakat, dalam konteks ini kemajuan yang terjadi pada media baru khususnya media sosial. Karena masyarakat informasi modern muncul sebagai hasil dari pengembangan inovasi dan teknologi baru (Hauer, 2017). Informan juga mengungkapkan alasan penggunaan stories highlight Instagram ini dikarenakan Instagram khususnya pada fitur stories mempunyai opsi yang beragam seperti filter atau efek yang banyak dan lebih menarik sehingga fitur ini dipilih dalam menyampaikan pesan daripada penggunaan Instagram feed yang perlu berpikir matang untuk mengunggah memori beserta caption pada fitur tersebut, sehingga stories tersebut nantinya dapat dipilih untuk dijadikan stories highlight di laman profil informan.

Kemudahan dan kepraktisan dari penggunaan stories highlight serta dapat dipilih dan tersimpan lama menjadi alasan informan lebih memilih fitur ini daripada mengunggah foto pada timeline atau feed mereka. Berikut pernyataan dari salah satu informan: "Kalau feed tuh harus think twice sebelum nge-upload, kalo highlight merasa lebih bebas tanpa mikir banyakbanyak, mau upload ya tinggal upload. Stories highlight tuh lebih menyederhanakan hidup lah" - informan 2 (ARR).

Berikut hasil observasi pada stories highlight Instagram kedua informan, yang menyisipkan filter atau efek pada stories mereka. 


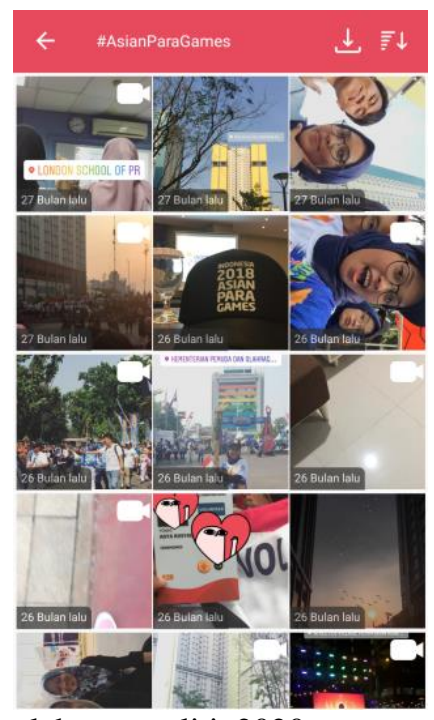

Sumber: olahan peneliti, 2020

Gambar 3 Stories Highlight dengan Efek

(informan 1)

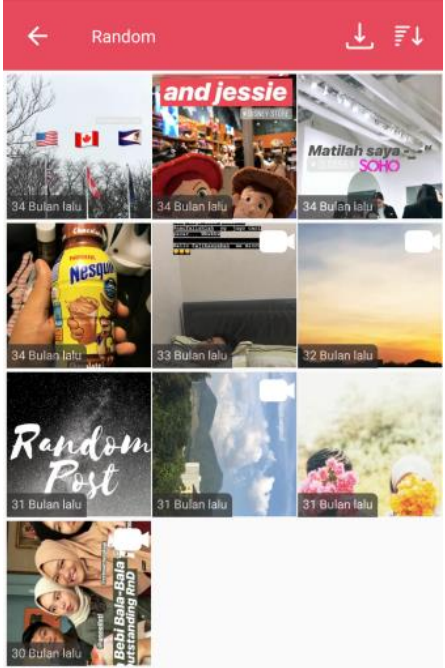

\section{Gambar 4 Stories Highlight dengan \\ Efek}

(informan 2)

Berdasarkan alasan yang dituturkan informan, serta observasi terhadap stories highlight Instagram keduanya, pesan atau informasi yang dikomunikasikan lebih beragam dengan adanya teks, gambar, video, filter bahkan emoji. Di mana hal ini sejalan dengan fenomena sosial stories Instagram yang digunakan 500 juta pengguna setiap harinya (Bohang, 2019). Semua ini berkaitan dengan alasan semakin beragamnya pilihan cara berkomunikasi di era digital, tidak hanya melalui audio dan video, bahkan dapat melalui simbol tertentu yang semakin unik dan canggih. Penelitian ini juga menguatkan konsep yang sesuai dengan ciri generasi milenial yaitu ingin praktis dan dinamis dalam kehidupannya (Budiati et al., 2018).

Kategori stories highlight yang dipilih informan pun ditentukan berdasarkan tema dari momen penting tertentu yang ingin diabadikan dan diingat. Pemilihan momen stories highlight dipilih hanya berdasarkan momen berharga yang dianggap penting untuk dikenang. Hal ini sesuai dengan literatur, di mana pengguna lebih mementingkan apa yang mereka posting dan bagaimana mereka mengekspresikan pesan mereka dalam postingan (Serafinelli, 2017). Ini sejalan dengan fenomenologi sosial Alfred Schütz yang mana dalam setiap tindakan yang dikembangkan, ada perasaan yang dengan sengaja berusaha untuk memenuhi harapan dan kebutuhan (Vieira et al., 2013).

\section{In-order-to Motives}

In-order-to motives adalah motif agar, yang bermaksud untuk mencapai tujuan di masa depan berdasarkan pada motif masa lalu (Muzzetto, 2006). Ada tiga tujuan yang diperoleh dari informan dalam menggunakan stories highlight Instagram. Pertama, untuk membentuk album digital yang terkonsep dan tersusun. Kedua informan menyatakan bahwa highlight dari kumpulan story dibuat menjadi album digital, yang diadopsi dari album foto konvensional. Album pada platform digital yang dibuat terkonsep akan mempermudah informan ketika ingin melihat kembali memori mereka, yang terdapat pada stories highlight. Dan album digital yang tersusun akan terlihat rapi dan menarik. Berikut hasil observasi pada 
kedua akun informan mengenai album digital yang menunjukkan runutan foto dalam album yang tersusun dengan diberikan judul sesuai kategori.

Sumber: olahan peneliti, 2020

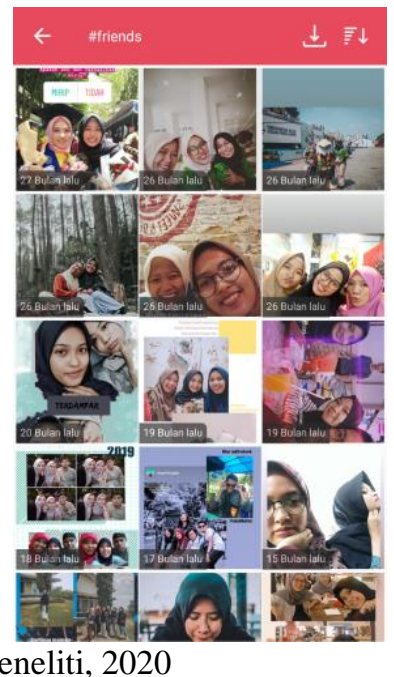

Gambar 5 Highlight dengan Judul \#Friends

(informan 1)

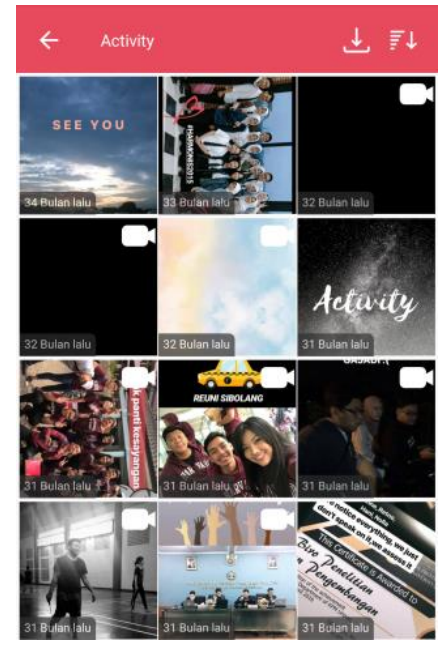

\section{Gambar 6 Highlight dengan Judul \\ Activity \\ (informan 2)}

Berdasarkan observasi yang dilakukan didapat hasil bahwa highlight Instagram dibuat seperti kumpulan foto dan/atau video pada album konvensional namun berada pada platform digital yang dipublikasikan secara online.

Motif agar ini juga sejalan dengan alasan kedua dari tujuan menggunakan stories highlight, yaitu agar memori yang dimiliki juga bisa dilihat orang lain. Informan mengaku menggunakan stories highlight agar cerita-cerita (stories) mereka dilihat orang lain atau pamer (show off). Alasan pamer juga mendasari kedua informan untuk pertama kali membuat akun Instagram mereka. Informan mengaku bahwa terdapat keinginan untuk disadari keberadaan atau eksistensinya oleh orang lain. Membagikan serta menunjukkan kegiatan dan pengalaman yang mereka lakukan adalah salah satu wujud yang dilakukan agar eksis. Dan alasan ketiga dari tujuan menggunakan stories highlight adalah agar informan dapat melihat kembali dan bersyukur atas apa yang pernah terjadi dalam hidup. Sehingga tidak merasa putus asa disaat mereka berada pada posisi sulit dalam hidup, karena mereka dapat melihat kembali memori yang pernah dicapai sebagai bentuk rasa syukur.

Berikut kutipan pernyataan informan 1, terkait hal ini: "Sebagai pengingat memori agar tetap bersyukur di kemudian hari, semisal jika lagi down. Aku bisa ngeliat lagi memorimemori atas perjalanan dan pencapaian aku selama ini"- informan 1 (ARY).

Dari segi tampilan, terdapat perbedaan tujuan antara kedua informan. Informan 1 memilih sampul (cover) berdasarkan gambar yang disukai tanpa memperhatikan estetika tertentu namun menarik bila dilihat orang lain. Berbeda halnya dengan informan 2 yang sengaja membuat sampul (cover) sendiri dan tatanan yang rapi untuk stories highlight dengan penyeragaman warna dan tulisan agar terlihat memiliki nilai seni.

Seperti pernyataan yang diungkap oleh informan 2: "Pengen showing that I am the good enough in arts gitu loh hahaha. Gue pengen keliatan rapih dan bagus, ya okee gitu. Gue 
tuh menata stories highlight gue itu di depannya itu gue samain tonenya, tulisannya. Jadi gue emang berniat untuk itu - cover" - informan 2 (ARR).

Perbedaan ini justru menimbulkan hal baru, bahwa pemilihan sampul mempunyai tujuan yang berbeda pada masing-masing informan, yang berkaitan dengan nilai keindahan atau estetika dan preferensi pribadi.

\section{Makna}

Makna berkaitan dengan aspek apa yang dialami oleh individu atau aktor sosial, yang terdapat pada tindakan (Muzzetto, 2006). Stories highlight Instagram berada pada posisi penting, karena merupakan bentuk album digital sebagai tempat penyimpanan memori atau momen penting dan membanggakan (olahan peneliti dari hasil wawancara pada kedua informan, 2020).

Sebelum adanya fitur stories highlight, penyimpanan secara analog seperti foto dan album cetak/fisik masih dilakukan pada memori lama ketika informan masih kecil, namun dengan munculnya stories highlight, terdapat kecenderungan untuk menyimpan momen yang pernah terjadi di dalam bentuk digital yaitu fitur stories highlight. Terdapat perubahan pola pikir masyarakat dalam melihat bagaimana konten media diproduksi dan didistribusikan. Semenjak munculnya media baru berbasis elektronik, media analog seperti teks, suara, gambar bergerak menjadi bentuk media digital (McMullan, 2017). Digitalisasi mendominasi perekaman, penyimpanan momen, dan pengkomunikasian pesan melalui media baru yang memungkinkan untuk membuat, memodifikasi dan berbagi konten, menggunakan alat yang relatif sederhana yang seringkali gratis atau murah (Olubunmi, 2016).

Memori menempatkan diri individu atau aktor sosial dalam kaitannya dengan masa lalu. Memori memungkinkan untuk mengingat kembali pengalaman, serta memeriksa dan menggunakannya untuk berbagai tujuan, termasuk mendokumentasikan dan mengkomunikasikan apa yang terjadi (Özkul \& Humphreys, 2015). Fitur stories highlight membantu dan mempermudah dalam mengingat memori masa lalu, sehingga memori yang pernah dibuat dan dimasukkan ke dalam stories highlight, pernah dan sering dilihat kembali oleh informan. Oleh sebab itu kedua informan mengakui bahwa penyimpanan atau pemeliharaan memori kini semakin banyak ditugaskan ke media elektronik dalam bentuk digital.

Dari pengumpulan data penelitian tampak bahwa antara penyimpanan memori secara digital melalui media baru dan makna saling terkait akan pengalaman individu atau aktor sosial yang mengalami kejadian tertentu. Hal ini dipengaruhi oleh alasan masa lalu (becausemotives) dan tujuan masa depan (in-order-to motives) yang memiliki persamaan. Becausemotives terdiri dari tiga alasan yakni mengikuti teman dan tren, memanfaatkan digitalisasi teknologi dan karena fitur stories highlight memiliki lebih banyak opsi yang menarik untuk menyampaikan pesan daripada fitur lain. In-order-to motives terdiri dari tiga tujuan yakni untuk membentuk album digital yang terkonsep dan tersusun, agar bisa dilihat orang lain serta agar dapat dilihat kembali dan bersyukur di masa mendatang atas kenangan juga pencapaian di masa lalu. Dan stories highlight merupakan suatu hal yang penting karena bermakna sebagai bentuk album digital untuk tempat menyimpan memori atau kenangan bagi informan sebagai generasi milenial. 
Meskipun terdapat perbedaan alasan oleh kedua informan dalam penggunaan fitur stories highlight, seperti pemilihan cover sesuai preferensi pribadi, namun hal itu tidak mengubah makna dari penggunaan fitur stories highlight bagi informan. Informasi yang ingin ditampilkan dari setiap stories highlight berbeda-beda, namun pengalaman yang didapat kedua informan mempunyai makna yang sama dalam menggunakan fitur stories highlight Instagram. Dengan motif menurut Alfred Schütz, kedua informan juga memiliki kesamaan dalam hal motif tersebut. Oleh sebab itu, penelitian ini dirasa cukup hanya dengan memilih dua informan, dikarenakan motif dan makna yang mereka alami memiliki inti yang sama.

\section{SIMPULAN}

Penelitian ini mengungkapkan fenomenologi sosial yang terjadi di masyarakat saat ini terutama pada media baru, Instagram. Secara keseluruhan, penelitian mengungkapkan motif penggunaan fitur stories highlight Instagram sebagai memori media bagi generasi milenial. Terdapat tiga motif sebab (because-motives) yang merupakan alasan masa lalu dalam menggunakan fitur stories highlight Instagram. Pertama, karena mengikuti teman dan tren. Alasan ini dikarenakan informan hidup dalam komunitas sosial yang membuatnya termotivasi untuk melakukan tindakan yang menarik dan sesuai kebutuhannya. Hal ini juga tidak terlepas dari fenomena menggunakan story pada media Instagram. Kedua, memanfaatkan teknologi media baru. Pemanfaatan ini menjadi suatu hal baru dari perkembangan teknologi dalam menyimpan di platform digital. Ketiga, karena fitur stories highlight memiliki lebih banyak opsi yang menarik untuk menyampaikan pesan kepada audiens daripada menyimpan memori di fitur lain. Semua ini berkaitan dengan alasan semakin beragamnya pilihan cara berkomunikasi di era digital, tidak hanya melalui audio dan video, bahkan dapat melalui simbol tertentu yang semakin unik dan canggih.

Selain itu, juga terdapat tiga motif agar (in-order-to motives) yang merupakan motif tujuan di masa depan dalam menggunakan fitur stories highlight Instagram. Pertama, agar membentuk album digital yang terkonsep dan tersusun, yang diadopsi dari album foto konvensional. Album pada platform digital yang dibuat terkonsep akan mempermudah informan ketika ingin melihat kembali memori mereka, yang terdapat pada stories highlight. Dan album digital yang tersusun akan terlihat rapi dan menarik. Kedua, ajang unjuk diri (show off) kepada orang lain. Adanya keinginan untuk disadari keberadaan atau eksistensinya oleh orang lain. Membagikan serta menunjukkan kegiatan dan pengalaman adalah salah satu wujud yang dilakukan agar eksis. Ketiga, agar dapat bersyukur atas kejadian yang pernah terjadi di masa lalu. Serta terdapat makna yang ditemukan dari fitur stories highlight bagi pengguna Instagram sebagai generasi milenial, yaitu fitur stories highlight Instagram sebagai album digital untuk menyimpan memori yang pernah terjadi di masa lalu.

Komunikasi melalui media baru (digital) diungkapkan dalam bentuk kumpulan memori pada stories highlight Instagram berdasarkan tema yang telah dikategorikan oleh pengguna yang tak lepas dari modernisasi teknologi informasi dan komunikasi. Stories highlight Instagram adalah bentuk menjaga masa lalu yang akan hadir di masa depan. Terdapat perubahan signifikan dalam penyimpanan memori atau kenangan pengguna dari bentuk analog ke digital. Digitalisasi perlahan bergerak menjadi komponen utama dalam penyimpanan memori atau kenangan di masa lalu. Terdapat kebaharuan pada penelitian ini 
bahwa perbedaan pemilihan sampul mempunyai tujuan yang berbeda pada masing-masing informan, yang berkaitan dengan nilai estetika dan preferensi pribadi.

Penelitian ini juga menemukan bahwa perspektif komunikasi dapat dilihat dari bagaimana cara informan sebagai generasi milenial membagikan pengalaman dan cerita mereka melalui stories highlight Instagram. Didapat juga hasil bahwa masyarakat modern digital menyimpan kenangan mereka dalam media penyimpanan digital dan perlahan meninggalkan media analog. Penelitian ini juga menguatkan konsep yang sesuai dengan ciri generasi milenial yaitu ingin praktis dan dinamis dalam kehidupannya.

Penelitian ini menemukan bahwa dalam fenomena sosial manusia memang berusaha memahami makna atas tindakan. Pada setiap tindakan yang dikembangkan, ada perasaan yang dengan sengaja berusaha untuk memenuhi harapan dan kebutuhannya yang disebut dengan motif. Sehingga tujuan dari penelitian untuk mengetahui motif penggunaan fitur stories highlight Instagram bagi generasi milenial pun terjawab.

Meski sudah menemukan tujuan dari penelitian ini, namun disarankan untuk penelitian di masa mendatang agar mengkaji lebih dalam mengenai komunikasi pada topik lain seperti kajian semiotika dari fitur stories highlight Instagram, yang dikaitkan dengan audiens digital. Selain itu penelitian selanjutnya bisa lebih menekankan konsep nostalgia yang dihadirkan memori pada media digital. Agar kehadiran fitur pada media digital dapat dieksplorasi dari berbagai sudut pandang.

\section{UCAPAN TERIMA KASIH}

Penulis menghaturkan terima kasih kepada para narasumber yang telah bersedia meluangkan waktu dan memberikan informasinya untuk penyusunan artikel ilmiah ini. Penulis juga berterima kasih kepada redaksi Jurnal Avant Garde dan reviewer atas saran yang telah diberikan. Terima kasih juga kepada semua pihak yang sudah membantu dalam terlaksananya penyusunan artikel ilmiah ini hingga selesai.

\section{DAFTAR PUSTAKA}

Amâncio. (2017). Put it in your Story: Digital Storytelling in Instagram and Snapchat Stories. Master Thesis, Uppsala Universitet.

Amaral, I. (2015). Instagram. In The SAGE Encyclopedia of Economics and Society. SAGE

Publications. https://doi.org/http://dx.doi.org/10.4135/9781452206905.n373

Bohang, F. K. (2019). Pengguna Harian Instagram Stories Tembus Angka 500 Juta. Diakses pada 17 Maret 2020, dari

https://tekno.kompas.com/read/2019/01/31/15320087/pengguna-harian-instagramstories-tembus-angka-500-juta

Budiati, I., Susianto, Y., Adi, W. P., Ayuni, S., Reagan, H. A., Larasaty, P., Setiyawati, N., Pratiwi, A. I., \& Saputri, V. G. (2018). Profil Generasi Milenial Indonesia. Kementerian Pemberdayaan Perempuan dan Perlindungan Anak.

Creswell, J. W. (2013). Qualitative Inquiry and Research Design: Choosing Among Five Approaches. SAGE Publications.

Finlay, L. (2012). Unfolding the phenomenological research process: Iterative stages of

“Seeing Afresh.” Journal of Humanistic Psychology, 53(2), 172-201. 
https://doi.org/10.1177/0022167812453877

Guay, F., Chanal, J., Ratelle, C. F., Marsh, H., Larose, S., \& Boivin, M. (2010). Intrinsic, identified, and controlled types of motivation for school subjects in young elementary school children. British Journal of Educational Psychology, 80(4), 711-735. https://doi.org/10.1348/000709910X499084

Gunderson, R., Stuart, D., \& Houser, M. (2020). A political-economic theory of relevance: Explaining climate change inaction. Journal for the Theory of Social Behaviour, 50(1), 42-63. https://doi.org/10.1111/jtsb.12224

Halik, A. (2018). Paradigma kritik penelitian komunikasi (pendekatan kritis-emansipatoris dan metode etnografi kritis). Jurnal Dakwah Tabligh, 19(2), 162-178.

Hauer, T. (2017). Technological determinism and new media. International Journal of English, Literature and Social Science, 2(2), 2456-7620.

Huang, Y. T., \& Su, S. F. (2018). Motives for instagram use and topics of interest among young adults. Future Internet, 10(8). https://doi.org/10.3390/fi10080077

Josina. (2017). Soal Fitur Baru Instagram: Stories Highlights dan Stories Archive. Diakses pada 20 Maret 2020, dari https://inet.detik.com/cyberlife/d-3757615/soal-fitur-baruinstagram-stories-highlights-dan-stories-archive

Kemp. (2020). Digital 2020: 3.8 Billion People Use Social Media. Diakses pada 18 Maret 2020, dari https://wearesocial.com/blog/2020/01/digital-2020-3-8-billion-people-usesocial-media

Kertamukti, R., Nugroho, H., \& Wahyono, S. B. (2019). Kontruksi Identitas Melalui Stories Highlight Instagram Kalangan Kelas Menengah. Jurnal ASPIKOM, 4(1), 26. https://doi.org/10.24329/aspikom.v4i1.502

Kuhn, A. (2010). Memory Texts and Memory Work: Performances Of Memory In And With Visual Media. Memory Studies, 3(4), 298-313. https://doi.org/10.1177/1750698010370034

Littlejohn, S.W., Foss, K. A. (2009). Encyclopedia of Communication Theory. SAGE Publications.

Logan, R. K. (2013). Language And Media as Extensions Of The Mind. AVANT. IV(2), 3144. https://doi.org/10.12849/40202013.0709.0002

Macon, J. M. (2017). User-generated content: An examination of users and the commodification of Instagram posts. Master Thesis, Colorado State University.

McMullan, J. (2017). A new Understanding Of 'New Media': Online platforms As Digital Mediums. Convergence, 26(2), 287-301. https://doi.org/10.1177/1354856517738159

Mustafa, I (2020). Pengguna Instagram di Indonesia Didominasi Wanita dan Generasi Milenial. Diakses pada 18 Maret 2020, dari https://www.goodnewsfromindonesia.id/2020/06/14/pengguna-instagram-di-indonesiadidominasi-wanita-dan-generasi-milenial

Muzzetto, L. (2006). Time and meaning in Alfred Schütz. Time \& Society, 15(1), 5-31. https://doi.org/10.1177/0961463X06061334

Neiger, M., Zandberg, E., \& Meyers, O. (2011). On media memory. In On Media Memory (Issue February 2016). https://doi.org/10.1057/9780230307070

Neuman, W. L. (2014). Social research methods: qualitative and quantitative approaches. In 
Teaching Sociology (Vol. 30, Issue 3). PERSON. https://doi.org/10.2307/3211488

Olubunmi, A. P. (2016). The emerging cyber media: The beginning of a new media and the end of old media. Online Journal of Communication and Media Technologies, 6(1), 119-128. https://doi.org/10.29333/ojcmt/2542

Özkul, D., \& Humphreys, L. (2015). Record and remember: Memory and meaning-making practices through mobile media. Mobile Media and Communication, 3(3), 351-365. https://doi.org/10.1177/2050157914565846

Qutoshi, S. B. (2018). Phenomenology: A philosophy and method of inquiry. Journal of Education and Educational Development, 5(1), 215. https://doi.org/10.22555/joeed.v5i1.2154

Rakhmawati, Y. (2019). Metode Penelitian Komunikasi (1st ed.). Putra Media Nusantara.

Rehman, A. A., \& Alharthi, K. (2016). An introduction to research paradigms in distance education. International Journal of Educational Investigations, 3(October), 51-59.

Serafinelli, E. (2017). Analysis of photo sharing and visual social relationships: Instagram as a case study. Photographies, 10(1), 91-111. https://doi.org/10.1080/17540763.2016.1258657

Seyfi, M., \& Uzuncarsili Soydas, A. (2017). The relationship between autobiographical memory and social media: Sharing childhood photographs on social media. Global Media Journal TR Edition, 8(15), 57-70.

Togar, H., Manik, P., \& Mayopu, R. G. (2019). Motivasi penggunaan media sosial Instagram di kalangan mahasiswa public relations Universitas Kristen Satya Wacana Salatiga. Jurnal Humaniora Yayasan Bina Darma, 5(1), 102-120.

Trujillo, J. (2018). Intersubjectivity and the sociology of Alfred Schutz. Bulletin d'analyse Phénoménologique, 14(7), 1-30.

Vieira, L., Schaurich, D., Padoin, S., Souza, I., Paula, C., \& Crossetti, M. (2013). Social phenomenology: analysis of academic production of graduate in nursing Brazil, 19792010. Revista de Pesquisa: Cuidado é Fundamental Online, 5(4), 652-660. https://doi.org/10.9789/2175-5361.2013v5n4p652

Walgito, B. (2010). Pengantar psikologi umum. Rajawali Pers.

Yusuf, M. (2014). Metode penelitian kuantitatif, kualitatif \& penelitian gabungan.

KENCANA. https://books.google.co.id/books?id=RnA-

$D w A A Q B A J \&$ printsec $=$ frontcover $\& h l=i d \# v=$ onepage $\& q=$ fenomenologi $\& f=$ false 